\title{
The Role of Philanthropic Funding in Building Research Evidence to Support an Aging Population: A Case Study from Ireland
}

\section{Andy Cochrane \& Sinéad McGilloway}

To cite this article: Andy Cochrane \& Sinéad McGilloway (2017) The Role of Philanthropic Funding in Building Research Evidence to Support an Aging Population: A Case Study from Ireland, Journal of Aging \& Social Policy, 29:3, 262-275, DOI: 10.1080/08959420.2017.1312207

To link to this article: https://doi.org/10.1080/08959420.2017.1312207

Accepted author version posted online: 31

Mar 2017.

Published online: 18 Apr 2017.

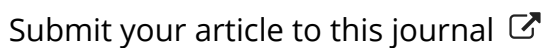

山 Article views: 156

Q View related articles $\sqsubset$

View Crossmark data $\nearrow$ 


\title{
The Role of Philanthropic Funding in Building Research Evidence to Support an Aging Population: A Case Study from Ireland
}

\author{
Andy Cochrane, $\mathrm{PhD}^{\mathrm{a}}$ and Sinéad McGilloway, $\mathrm{PhD}^{\mathrm{b}}$ \\ aPostdoctoral Researcher, Department of Psychology, National University of Ireland Maynooth, \\ Maynooth, Ireland; 'birector, Mental Health and Social Research Unit, Department of Psychology, \\ National University of Ireland Maynooth, Maynooth, Ireland
}

\begin{abstract}
This case study examines the role of philanthropic funding in building capacity for aging research in Ireland, and how this investment has addressed the lack of evidence to support planning for an aging population. The funding has supported a range of initiatives including the national longitudinal study on aging (TILDA), the creation of three professorships/chairs, and the establishment of four new research centers. Important potential outcomes are emerging across other domains including research-informed policy development and the generation of health benefits. The efforts of academic researchers to ensure that their findings are readily accessible to end users and to forge robust working relationships with all stakeholders have helped to enhance the use of research findings. Overall, philanthropy has played a pivotal role in building capacity, infrastructure, and expertise in academic settings in Ireland. Moreover, this work provides an excellent example of how such efforts can begin to inform effective planning and service provision.
\end{abstract}

\section{ARTICLE HISTORY}

Received 29 December 2015

Accepted 2 February 2017

\section{KEYWORDS}

Aging research; capacity building; philanthropy

\section{Introduction}

The continuous aging of the world's population has been well documented (Lutz, Sanderson, \& Scherbov, 2008) and presents a considerable challenge for health and social care systems in meeting the demands of increasing numbers of older people ("Global elderly care in crisis," 2014). Demographic change also presents a challenge across other policy areas including the labor market, social protection systems, and pensions (Gløersen et al., 2016). While Ireland currently has the highest proportion of young people ( $0-14$ years) in the European Union and the second lowest proportion of older people (aged 65 and older; Central Statistics Office, 2015), the population is projected to age rapidly into the future when compared to most other European countries. For example, there were approximately 0.5 million people aged 65 and

CONTACT Andy Cochrane andy.cochrane@nuim.ie National University of Ireland Maynooth, John Hume Building, Maynooth, County Kildare, Ireland. 
older living in Ireland in 2011, and this population is expected to double by 2031 (Centre for Ageing Research and Development Ireland [CARDI], 2012).

Historically, there has been little information or robust evidence on the experience of aging in an Irish context (O'Shea \& Conboy, 2005). Thus, rigorous high-quality research is vital to inform the kind of appropriate and effective service planning and policy development required to manage this significant demographic change and its likely consequences. Research on the strategic issues facing an aging population is particularly important in order to minimize the squandering of scarce resources on projects with limited application or relevance.

Philanthropic organizations are uniquely placed to use their funding, authority, and flexibility to support rigorous interdisciplinary research and provide evidence to address societal grand challenges and our most pressing problems (Gruman \& Pager, 2002). For example, Grantmakers in Aging, a membership organization for philanthropies dedicated to improving the experience of aging, has encouraged foundations to assume a more proactive leadership role in addressing demographic change (Torres-Gill, 2007). Philanthropic bodies/foundations can also focus resources on those issues that, while important to aging and older adults, may be unlikely to attract traditional funding revenue (Kolb, 2007). While only 2\% of American institutional philanthropy is allocated for aging programs (The Foundation Center, 2014), the philanthropic sector can help to increase awareness and shape public discourse around the aging population while informing policy responses to demographic change through innovative activities, unhindered by political debates and market forces (Torres-Gill, 2007).

The Atlantic Philanthropies (Atlantic) is one such international philanthropic organization that has supported many causes in countries across the world including South Africa, Vietnam, Bermuda, Northern Ireland, and the Republic of Ireland. Atlantic established a number of programmes in the Republic of Ireland in 2003, one of which was its ambitious Ageing Programme. The overarching aim of this large-scale program was to improve the quality of life for older adults by strengthening the aging field and informing a more effective use of government and nongovernment resources to meet the needs of older adults and their families. Since 2005, Atlantic, through its Ageing Programme in Ireland, has responded to the information gaps and concomitant lack of research-informed planning for an aging population by investing more than $\$ 150$ million in aging research. This funding compares to the $\$ 37$ million allocated annually to universities and health systems by the Health Research Board, the leading health research agency in Ireland, and \$32 million awarded in 2016 across all disciplines by the Irish Research Council (nationally funding body supporting research and the education and skills development of researchers). 
Typically, proposals for Atlantic funding are by invitation only, and potential grantees are usually required to have demonstrated some evidence of their current and future capacity for success. Originally, Atlantic's approach (and its overall aim to transform the lives of disadvantaged and vulnerable groups) was to bring a broad initial understanding of pertinent issues and developments to guide the early stages of any research grant/ process that might be eligible for funding. Intensive discussions and consultations with organizations/prospective grantees prior to the award of grants help to guide and inform project specification in line with Atlantic's priorities.

The case study that is the focus of this paper was part of a larger ongoing evaluation of Atlantic's support of the aging sector in Ireland. The aims of this substudy were to (a) monitor and describe Atlantic's investment in Ireland in developing research capacity during 2008 to 2013 through a range of activities across the academic sector and (b) explore and critically appraise the potential of this work to inform and influence policy and practice designed to support Ireland's aging population. The study involved three main elements: (a) face-to-face interviews with principal investigators who had been awarded grant(s) $(n=9)$; (b) a subsequent survey in 2011 to grantees; and (c) a second survey 2 years later. The data collected were supplemented by a comprehensive review and analysis of a series of key documents (e.g., organizational reports, websites, grant proposals, and progress reports). This case study focuses, in particular, on 13 grants awarded to four academic institutions/centers in Ireland; two of the grants involved a collaboration between two universities. The first of the grants included in this analysis was awarded in 2004, but most were more recent and the activities related to the funding were ongoing at the time of data collection.

\section{Building capacity}

Capacity building is central to all of Atlantic's work, and since 2005 four major centers of expertise in aging research have been established in Ireland. Collectively, these centers reflect the breadth and complexity of gerontological research by focusing on a wide range of issues. Specifically, these are (a) social gerontology (Irish Centre for Social Gerontology, Galway); (b) applied research including technologies that support "aging in place" (Netwell Centre, Dundalk); (c) interdisciplinary research and education in hospital and community care (Centre for Gerontology and Rehabilitation, Cork); and (d) clinical services, research, training, and education (Mercer Institute for Successful Ageing, Dublin). The work of these centers has been enhanced by the creation of three professorships/chairs in response to the need for academic leadership in aging, and these posts have increased the opportunities for innovative, cross-disciplinary education and research. For example, the 
professorship in gerontology and rehabilitation and the associated specialist center have provided a focus for teaching and research that had been previously absent in that particular region of Ireland. Expertise in social gerontology has also been consolidated and expanded by the creation of a professorship in an existing Atlantic-supported center. Finally, crossdisciplinary and innovative educational and research opportunities have developed as a direct result of the creation of a professorship in neural engineering as a joint appointment between a School of Medicine and School of Engineering. This has ensured that the senior academic has direct access to clinical colleagues and that every research project undertaken in neural engineering has a clinical collaborator, thereby helping to facilitate greater interdisciplinary research than was previously the case. The two schools have confirmed that they will continue to fund this joint post following the initial investment by Atlantic.

Although there has been growth since the 1970s in aging research across Europe, there has been a lack of investment at the postgraduate level and a generally poor career structure in the field (Warnes \& Phillips, 2007). This has also been the case in Ireland and, in recognition of this, two of Atlantic's grants focused specifically on supporting postgraduate education in two research groups, with an emphasis on dementia and social policy, respectively. In addition, doctoral training has been enhanced in all four centers of expertise and candidates have received leveraged funding from national bodies including the Irish Research Council and the Health Research Board, the lead organization in Ireland supporting and funding health research (Nason et al., 2008). Of importance, several of the graduates who have been supported through Atlantic funding have been able to continue working in the sector in other roles such as postdoctoral researchers and nongovernmental organization (NGO) policy and research managers. Furthermore, the Atlantic-funded CARDI (2015) has initiated a Leadership Programme that aims to create a new generation of high-quality leaders in aging research on the island of Ireland. This program should begin to address the lack of a robust career structure for researchers following postgraduate training as well as providing suitable successors to the current leaders in Irish academic aging research.

\section{Generating a robust evidence base}

Another of Atlantic's goals is to build an appropriate evidence base around issues of public concern, including aging. Unlike many other developed countries, there had previously been no large-scale population-based studies in Ireland to inform aging research (Kearney et al., 2011). Atlantic's flagship aging project-the Irish Longitudinal Study on Ageing (TILDA) - was launched in 2008 following the award of additional joint funding by the 
Department of Health (DoH) and Irish Life (a financial services organization); this is recognized internationally as one of the most comprehensive longitudinal studies ever undertaken. A wide range of information on physical, mental, and cognitive health, as well as extensive economic and social data, are collected over time on more than 8500 participants aged 50 and older. Data collection started in 2009, and the third wave commenced in 2014. Participants are reinterviewed every 2 years and invited to complete a comprehensive health assessment every 4 years for a 10 -year period. TILDA is providing (and will continue to provide) important high-quality evidence to inform, and evaluate the impact of, policy initiatives over time. Of importance, TILDA is also harmonized with leading international research and is part of a collaboration of longitudinal studies examining the generalizability of findings across nations (e.g., Canada, United Kingdom) and birth cohorts (Integrative Analysis of Longitudinal Studies of Aging).

Historically, most research and research funding in the aging field in Ireland has tended to focus on the biomedical field (e.g., basic science and medical geriatrics), with little or no liaison between disciplines (Warnes \& Phillips, 2007). While a relatively large proportion of Atlantic's aging-related funding has been directed toward medical gerontology and health-related research, there has also been considerable support for other domains as recommended in the EU-funded FUTURAGE: A Road Map for Ageing Research (2011). These include, for example, a demonstration housing project located in the Northeast of Ireland, consisting of 16 purpose-built smart homes equipped with sensor and interactive technology to support independent living (Doyle, Kealy, Loane, \& Walsh, 2014) and research exploring how people of different ages living in Ireland think about, and engage in, intergenerational relationships (Scharf, Timonen, Carney, \& Conlon, 2013).

While recognizing that knowledge dissemination may not be sufficient to ensure the use of research evidence in decision making (Straus, Tetroe, \& Graham, 2009), there has been a substantial increase in academic publications from Ireland related to aging research since 1990 (sourced from Scopus database, December 2015). This increase cannot solely be attributed to funding from Atlantic; nevertheless, 5 of the top 10 most prolific authors identified during this period (1990-2014) were involved directly in Atlanticsupported research. However, a bibliometric analysis that relies solely on research published in academic journals may not provide a sufficiently accurate or comprehensive snapshot of output for some of the research teams supported by Atlantic. For example, some groups have an alternative "culture" of dissemination that focuses on reports and presentations, which can often reach a wider and more diverse audience than academic journals. Indeed, this kind of adaptation of research outputs to meet the needs of users is a key predictor of the uptake of research knowledge (Landry, Lamari \& Amara, 2003). Nevertheless, universities still tend to value the publication of 
research in international, high-impact peer-reviewed journals, and while this knowledge may not necessarily translate easily into policy and practice, academic career paths continue to be shaped by publication rates (van Dalen \& Henkins, 2012).

Critically, Atlantic's funding has allowed researchers to develop vital links and collaborations with interdisciplinary international teams, researchers, and research groups. For example, a visiting scholar scheme, part of the funding for research into aging in rural communities, has provided a useful context for building relationships with international researchers. Atlantic-supported centers have also hosted major international meetings (e.g., a Cultural Gerontology conference in Galway in 2014) and helped to bring to Dublin the International Association of Gerontology and Geriatrics European Region Congress in 2015. In addition, the recognition of two of Atlantic-supported institutions as "centres of excellence" by the Global Ageing Research Network has linked these researchers to more than 450 international members of the network. These relationships not only help to strengthen research programs and their potential for impact but also are of critical importance when competing for international funding (e.g., Horizon 2020)-clearly a key element in developing research capacity and enhancing Ireland's international reputation as a growing center for aging research.

\section{Informing policy development}

Changes to policy and practice are frequently the result of accumulative evidence rather than a single project or program of research (Kalucy, Bowers, McIntyre, Hordacre, \& Reed, 2009). In addition, the process of translating research findings into practice and policy is an indirect one, and it can often take many years for findings to result in sustainable (and measurable) change (Grimshaw, Eccles, Lavis, Hill, \& Squires, 2012). Together, these issues make the attribution of defined outcomes to any specific grant/source of funding particularly difficult. Furthermore, there is often a fragile relationship between research evidence and the, ultimately, political considerations that shape policy (Nutbeam, 2004). It has been critical, therefore, for researchers to, among other things, establish strong links and ongoing consultation with the potential end users of their work, including relevant government departments (Hagan Hennessy \& Walker, 2011). While acknowledging the inherent difficulty in attributing precise influential factors in policy formation, Atlantic-supported research has been extensively referenced in key documents designed to inform policy including, for example, reports related to the funding of home-based care (National Economic and Social Forum, 2009) and nursing home care (Office of the Ombudsman, 2010). 
Of importance, the DoH in Ireland is represented within TILDA's governance structure, which maximizes their direct involvement with the data and findings. Indeed, the DoH has directly informed TILDA of its pending research needs and interests, thereby ensuring that the findings from TILDA will have relevance, both in terms of generating new knowledge/ academic outputs and in informing policy. In addition, as a longitudinal study, there is a unique opportunity for the TILDA researchers not only to help shape policy but also to help monitor and assess the outcomes of policy initiatives and interventions.

Atlantic's work in helping to build the capacity both of research groups and the NGO sector was also crucial in ensuring government commitment, in 2010, to the development of a National Dementia Strategy, which was subsequently published in 2014 (Department of Health, 2014). Specifically, Atlantic commissioned and funded a major research project that provided the vital evidence base to support the development of this strategy (Cahill, O'Shea, \& Pierce, 2012). This research also provided a useful basis for the lobbying activities of voluntary groups concerned with dementia care. Furthermore, Atlantic supported several years of advocacy and political engagement, for example, by the Alzheimer Society of Ireland, all of which helped to progress this vital strategy. Atlantic grantees from both academia and the NGO sector, including the umbrella organizations Older and Bolder and Ageing Well Network (which they had helped to create), have also helped to inform the National Positive Ageing Strategy (Department of Health, 2013). Nevertheless, there is still a considerable amount of work required to ensure that decision makers ensure the effective use of research evidence to support the full implementation and evaluation of relevant policies and strategies.

\section{Health and broader economic impact}

It is not always easy to track the implementation of research findings into clinical practice, but the development of a greater understanding of aging through the education of both medical students and other professionals should help to promote more age-friendly practices across the health sector. Specific research projects funded by Atlantic have directly influenced patient care; for example, improved methods for predicting and assessing delirium are already helping to ensure prompt interventions in hospitalized older adults. Assessment tools have also been developed to identify older adults who are at risk for adverse outcomes (e.g., residential care, unplanned hospitalization) and, when fully implemented, will enable early interventions to target those most in need (Leahy-Warren et al., 2015). The Atlanticfunded audit of dementia care in acute care hospitals (Bhangu et al., 2016) revealed several areas of care that need to be improved, including assessment 
and discharge planning; these findings highlight the need to develop policies and care pathways to meet the complex needs of patients as well as providing baseline evidence from which to assess the effectiveness of any changes in practice. A recent grant supporting an extensive research program aimed at dementia prevention has the potential to help older adults maintain their cognitive health and independence (e.g., Hannigan, Coen, Lawlor, Robertson, \& Brennan, 2015).

In addition, the first three waves of TILDA have already highlighted important issues surrounding health inequalities and the prevalence and underdiagnosis of some physical and mental health disorders (e.g., atrial fibrillation, obesity, hypertension, depression) in the older population. This research has helped, among other things, to inform a clinical trial on the monitoring of heart arrhythmias or atrial fibrillation (Bhangu et al., 2016). Such clinical trials provide a useful means by which research findings from observational studies may be translated and implemented in clinical practice. The TILDA findings have also had other health, policy, and cost implications. For example, the findings relating to the use of statins in one cohort revealed a gap between clinical guidelines and practice, with the undertreatment of those with clinical evidence of cardiovascular disease; this demonstrates a need to improve both the primary and secondary prevention of cardiovascular disease (Murphy et al., 2015). Furthermore, TILDA's comprehensive data set provides valuable evidence on health care utilization and medication use among adults older than 50, and this information may be used to determine how to best generate savings and target resources.

The austerity measures implemented by the Irish government in the context of the recent financial and economic downturn (beginning in 2008) not only seriously curtailed social and health care spending but also imposed severe economic constraints on the introduction of new products, services, and interventions within the health service. This highlights a need to demonstrate the cost-effectiveness of any new initiative/service that is developed as a result of Atlantic-supported research, particularly at a time when resources are limited. For example, the recent audit of the care of people with dementia in acute care hospitals suggests that the overall cost of dementia care could be reduced if the detailed recommendations were implemented, in addition to improving outcomes for patients (Timmons et al., 2016). Nevertheless, until the economic situation improves, the mid- to long-term impact of research aimed at generating new products or changes in service delivery may be negatively affected.

The changing economic context has also impacted other funding sources in Ireland, and yet without additional investment research activities can quickly stall. Of importance, Atlantic-supported researchers have been able to leverage additional external funding for ongoing and new research 
projects. Continued success in competing for national and international funding will become increasingly important as Atlantic has now completed their grant-making activities in Ireland.

\section{Discussion}

The collective findings from our case study indicate that the investments made by philanthropic organizations-in this case, The Atlantic Philanthropies-can make important and vital contributions to improving the understanding of, and expanding our knowledge on, aging. Specifically, Atlantic has been able to build capacity and generate robust evidence in an Irish context by supporting and appropriately resourcing strong academic researchers. This has provided the necessary foundation for subsequent developments including informing policy and practice. The context within which research is communicated and potentially acted on is clearly important (Davies, Nutley, \& Walter, 2005). The work outlined in this case study was largely conducted during a financial and economic crisis in Ireland (and elsewhere), which has seriously curtailed social and health care spending, with potentially negative consequences for vulnerable older citizens. In addition, there are considerable challenges in ensuring that older people's issues and concerns do not become sidelined in both research funding and policy debates during a period of economic instability. This has perhaps made Atlantic's investment even more crucial for the development and expansion of aging research capacity in Ireland.

Philanthropic foundations can set their own policy agenda without input from others through their independent funding choices (Eikenberry, 2006). Of importance, the research priorities of Atlantic reflect those identified by Futurage (2011), and grants that are more recent were informed by the findings emanating from earlier investments. In addition, the investments made by Atlantic appear to have enabled researchers to leverage additional financial support from national and international funding bodies for followup programs of work.

Considerable progress has been achieved in increasing capacity through the training and education of researchers across the domains of gerontology. This is of vital importance as doctoral training "is a primary progenitor of new knowledge, which is crucial to the development of a prosperous and developed society" (Directorate-General for Research and Innovation, 2011, p. 1). Critically, Atlantic has done much to support postgraduate education through the direct funding of doctoral work and by enhancing the capacity of established and newly created research centers. The success of these centers, coupled with clearly articulated research objectives and a strong track record, have done much to ensure the continued funding, for example, of the senior academic posts/professorships. Nevertheless, there may be a need for the 
universities to ring-fence research time for those senior researchers with considerable clinical and teaching commitments and/or offer more support in the form of additional administrative and teaching staff. Undoubtedly, the ongoing support, both financial and practical, of the universities in which the centers are located will be critical as Atlantic winds down its funding activities.

The funding of collaborative research programs involving a number of institutions and disciplines (e.g., TILDA) has helped to improve the infrastructure and expertise beyond the core of Atlantic's grantees. This is of particular importance because Atlantic has tended to fund only a small cohort of grantees, and its influence in the aging sector ought to be more widespread to ensure that any positive changes in the sector are sustained following Atlantic's exit. It is encouraging that a recent review indicated that aging, from the "cellular to the personal" (CARDI, 2014, p. 10), is increasingly viewed as a research priority in many university settings across the island of Ireland.

While the research supported by Atlantic is certainly extensive in range and complexity, there have been some gaps. For instance, considerable work has been undertaken to reduce the burden of dementia, but arguably, there is a need for a more direct focus on prevention to reduce the burden of other chronic diseases including, for example, depression, arthritis, and diabetes. In addition, more could be done to expand the research agenda to explore initiatives and services that help older people to live independent and active lives, as well as addressing age-related inequalities and disparities in health.

Scientific research is an important driver of innovation in public policy and in the development and improvement of services and products within the aging sector (Futurage, 2011). However, only rarely will the impact of research on policy choices be direct and easily identifiable. Instead, it has been argued that research provides "a background of empirical [generalizations] that creep into policy deliberation" (Weiss, 1980, p. 381, cited by Davies, Nutley, \& Walter, 2005); capturing such influences in order to assess research impact poses considerable methodological challenges (Oliver, Innvar, Lorenc, Woodman, \& Thomas, 2014). Nevertheless, it would appear that Atlantic-supported researchers have begun to ensure that the research they have conducted has been relevant and potentially usable in a policy context to support planning for an aging population. In addition, the influence of Atlantic itself has helped to create opportunities for joint actions with local and national government departments.

While acknowledging that the process of knowledge transfer/translation is not always direct, the evidence suggests that considerable progress has been made in enhancing pathways and relationships to support and facilitate the effective transfer of research findings to policy makers, organizational decision makers, practitioners, and consumers. This is crucial in 
terms of moving toward successfully informing policy and practice in the short, medium, and longer term. Much more work is needed on this front -by researchers, practitioners, and policy makers alike-to ensure that appropriate, effective, and timely knowledge translation and exchange takes place and helps to inform policy and practice in real and meaningful ways.

A particularly good example of Atlantic's influence and impact has been the successful rollout of the Age Friendly Cities and Counties program and ethos across Ireland. Arguably, however, while this is an impressive initiative/development, there could have been greater academic input in all stages of the program. This would have helped to ensure, for example, that any policy initiatives were evidence-based and that key indicators of improvement were built into the program at an earlier stage. In addition, a robust evaluation of the processes involved in the program from the beginning would have provided a valuable resource for other jurisdictions wishing to become more age-friendly.

This need for the systematic use of research-based evidence to inform policy and practice would appear to be addressed, in part, by a new Atlantic-supported program, cofunded by the $\mathrm{DoH}$, entitled the Healthy and Positive Ageing Outcomes Initiative. The intended outputs of this program will include the identification of key national indicators of older people's health and well-being and the publication of regular "State of the Nation" older persons' reports that will link changes in the lives of older people to policy development. The proposed integration of the TILDA data set with information collected locally as part of the Age Friendly initiative and other research activities should also help to provide a comprehensive framework to increase knowledge around the factors contributing to health and well-being in older people.

In summary, a number of key lessons for funders have emerged from this case study. Specifically, it is useful for philanthropic organizations to retain the freedom and flexibility to identify and target issues that do not normally attract research investment yet help to promote a wider understanding of aging. Priorities may shift over the course of a program of research as new findings emerge, and these may help to inform subsequent rounds of funding. Real and meaningful change takes time, and measuring the impact of any long-term funding strategy, as well as the effects of contextual factors such as the changing economic climate, can be challenging. Therefore, robust evaluation and knowledge translation plans should be essential components of research proposals, alongside the development of key indicators with which to measure outcomes. Investment in the training and education of both clinicians and researchers can assist with the transfer of evidence into practice and build research capacity respectively. Finally, effective working relationships with policy makers and other stakeholders can maximize the impact and influence of funders while ensuring that the evidence generated from research informs policy and practice. 


\section{Conclusions}

All of the evidence to date suggests that an exciting process of systemic, transformative change within aging research in academia is now well underway in Ireland as a result of the investments made by Atlantic during an approximate 12-year period. The program has successfully enhanced research knowledge and built critical mass and infrastructure while helping to develop skills and networks, all of which, collectively, have helped to establish the international standing of Ireland as a center of excellence for aging research. Of importance, research evidence is now available, and will continue to emerge, to inform the development of policies, practices, and services to support the aging population, not only in Ireland but also farther afield. It is now of critical importance that the research community is able to capitalize on the existing energy and momentum now that Atlantic's period of funding has ended.

Atlantic has now exited the field in Ireland (as of December 2016) and is winding down (or has wound down) its grant-making activities in other jurisdictions in which it has operated. While this paper has focused on Atlantic's investment in aging, the organization has supported work addressing a range of social issues across the lifespan in both Ireland and several other countries. Thus, those working in aging research and associated activities should continue to engage with funding partners previously considered to be outside the traditional aging realm. This is particularly important at a time of limited resources and will help to ensure that philanthropy plays a critical role in sustaining the efforts needed to meet the demands and opportunities presented by the increasingly aging population (Feather, 2015).

\section{Acknowledgments}

We wish to extend our thanks to the grantees who generously gave of their time and expertise and the support staff at The Atlantic Philanthropies. We also would like to thank Michael Donnelly for his helpful comments on earlier drafts of this article.

\section{Disclosure}

The study is part of a larger evaluation commissioned by The Atlantic Philanthropies. The funder did not influence the overall findings or the content of this paper.

\section{References}

Bhangu, J., McMahon, C. G., Hall, P., Bennett, K., Rice, C., Crean, P., ... Kenny, R.-A. (2016). Long-term cardiac monitoring in older adults with unexplained falls and syncope. Heart, 102, 681-686. doi:10.1136/heartjnl-2015-308706

Cahill, S., O’Shea, E., \& Pierce, M. (2012). Creating excellence in dementia care. A research review for Ireland's national dementia strategy. Dublin, Ireland: Trinity College Dublin. 
Central Statistics Office. (2015). Measuring Ireland's progress 2013. Dublin, Ireland: Author. Retrieved from cso.ie/en/releasesandpublications/ep/p-mip/measuringirelandsprogress2013/

Centre for Ageing Research and Development in Ireland (CARDI). (2012). Ageing statistics for Ireland North and South. Dublin/Belfast, Ireland: Author.

Centre for Ageing Research and Development in Ireland (CARDI). (2014). A picture of ageing research in Ireland, North and South. Dublin/Belfast, Ireland: Author.

Centre for Ageing Research and Development in Ireland (CARDI). (2015). CARDI fellow leadership programme in ageing research. Dublin/Belfast, Ireland: Author.

Davies, H., Nutley, S., \& Walter, I. (2005). Assessing the impact of social science research: Conceptual, methodological and practical issues, a background discussion paper for ESRC symposium on assessing non-academic impact of research. Retrieved from www.odi.org/ sites/odi.org.uk/files/odi-assets/events-documents/4381.pdf

Department of Health. (2013). Positive ageing starts now! The National Positive Ageing Strategy. Dublin, Ireland: Author.

Department of Health. (2014). The Irish national dementia strategy. Dublin, Ireland: Author.

Directorate-General for Research and Innovation. (2011). Report of mapping exercise on doctoral training in Europe. 'Towards a common approach. Brussels, Belgium: European Commission.

Doyle, J., Kealy, A., Loane, J., \& Walsh, L. (2014). An integrated home-based self-management system to support the wellbeing of older adults. Journal of Ambient Intelligence and Smart Environments, 6(4), 359-383.

Eikenberry, A. M. (2006). Philanthropy and governance. Administrative Theory and Praxis, 28(4), 586-592.

Feather, J. (2015). Engaging private philanthropy in aging: It's time for a new approach. Generations, 39(3), 68-71.

Futurage. (2011). A road map for European ageing research. Retrieved from http://futurage. group.shef.ac.uk/road-map.html

Global elderly care in crisis [Editorial]. (2014). The Lancet, 383, 927. 10.1016/S0140-6736(14) 60463-3

Gløersen, E., Drăgulin, M., Hans, S., Kaucic, J., Schuh, B., Keringer, F., \& Celotti, P. (2016). The impact of demographic change on European regions. European Union Committee of the Regions. Retrieved from http://cor.europa.eu/en/documentation/studies/Documents/The\% 20impact\%20of\%20demographic\%20change \%20on\%20European\%20regions/Impact_ demographic_change_european_regions.pdf

Grimshaw, J. M., Eccles, M. P., Lavis, J. N., Hill, S. J., \& Squires, J. E. (2012). Knowledge translation of research findings. Implementation Science, 7(50). Retrieved June 30, 2015, from http://www.implementationscience.com/content/7/1/50

Gruman, J., \& Pager, D. (2002). Health research philanthropy in a time of plenty: A strategic agenda. Health Affairs, 21(5), 265-269. doi:10.1377/hlthaff.21.5.265

Hagan Hennessy, C., \& Walker, A. (2011). Promoting multi-disciplinary and inter-disciplinary ageing research in the United Kingdom. Ageing and Society, 31(1), 52-69. doi:10.1017/S0144686X1000067X

Hannigan, C., Coen, R. F., Lawlor, B. A., Robertson, I. H., \& Brennan, S. (2015). The NEIL memory research unit: Psychosocial, biological, physiological and lifestyle factors associated with healthy ageing: Study protocol. BMC Psychology, 3(20). doi:10.1186/s40359015-0079-y

Kalucy, L., Bowers, E. J., McIntyre, E., Hordacre, A.-L., \& Reed, R. (2009). Exploring the impact of primary health care research. Flinders, Australia: Primary Health Care Research \& Information Services. 
Kearney, P. M., Cronin, H., O’Regan, C., Kamiya, Y., Savva, G. M., Whelan, B., \& Kenny, R.A. (2011). Cohort profile of the Irish longitudinal study on ageing. International Journal of Epidemiology, 40(4), 877-884. doi:10.1093/ije/dyr116

Kolb, P. J. (2007, Summer). A snapshot of aging and philanthropy today. Generations, pp. $17-21$.

Landry, R., Lamari, M., \& Amara, N. (2003). The extent and determinants of the utilisation of university research in government agencies. Public Administration Review, 63(2), 192-205.

Leahy-Warren, P., O'Caoimh, R., FitzGerald, C., Cochrane, A., Svendrovski, A., Cronin, U., \& Molloy, D. W. (2015). Components of the risk instrument for screening in the community (RISC) that predict public health nurse perception of risk. Journal of Frailty and Aging, 4 (3), 149-154.

Lutz, W., Sanderson, W., \& Scherbov, S. (2008). The coming acceleration of global population ageing. Nature, 451, 716-719. doi:10.1038/nature06516

Murphy, C., Bennett, K., Fahy, T., Shelley, E., Graham, I., \& Kenny, R. A. (2015). Statin use in adults at high risk of cardiovascular disease mortality: A cross sectional analysis of baseline data from the Irish Longitudinal Study on Ageing (TILDA). BMJ Open, 5, e008017. doi:10.1136/bmjopen-2015-008017

Nason, E., Janta, B., Hastings, G., Hanney, S., O’Driscoll, M., \& Wooding, S. (2008). Health research-Making an impact. The economic and social benefits of HRB-funded research. Dublin, Ireland: Health Research Board.

National Economic and Social Forum (2009). Implementation of the home care package scheme. Dublin, Ireland: Author.

Nutbeam, D. (2004). Getting evidence into policy and practice to address health inequalities. Health Promotion International, 19(2), 137-140. doi:10.1093/heapro/dah201

Office of the Ombudsman. (2010). Who care? An investigation into the right to nursing home care in Ireland. Dublin, Ireland: Author.

O'Shea, E., \& Conboy, P. (2005). Planning for an ageing population: Strategic considerations. Dublin, Ireland: National Council on Ageing and Older People.

Oliver, K., Innvar, S., Lorenc, T., Woodman, J., \& Thomas, J. (2014). A systematic review of barriers to and facilitators of the use of evidence by policymakers. BMC Health Services Research, 14, 2. doi:10.1186/1472-6963-14-2

Scharf, T., Timonen, V., Carney, G., \& Conlon, C. (2013). Changing generations: Findings from new research on intergenerational relations in Ireland. Galway and Dublin, Ireland: NUIG and TCD.

Straus, S. E., Tetroe, J., \& Graham, I. (2009). Defining knowledge translation. Canadian Medical Association Journal, 181(3-4), 165-168. doi:10.1503/cmaj.081229

The Foundation Center. (2014). Grants for the aging. New York, NY: Author.

Timmons, S., O’Shea, E., O’Neill, D., Gallagher, P., De Siún, A., McArdle, D., ... Kennelly, S. (2016). Acute hospital dementia care: Results from a national audit. BMC Geriatrics, 16, article 113. doi:10.1186/s12877-016-0293-3

Torres-Gill, F. M. (2007, Summer). Policy advocacy for an aging society: Philanthropy and social change. Generations, pp. 35-40.

van Dalen, H. P., \& Henkins, K. (2012). Intended and unintended consequences of a publishor-perish culture: A worldwide survey. Journal of the Association for Information Science and Technology, 63(7), 1282-1293.

Warnes, T., \& Phillips, J. (2007). Progress in gerontology: Where are we going now? In M. Bernard, \& T. Scharf (Eds.), Critical perspectives on ageing societies (pp. 139-155). Bristol, United Kingdom: The Policy Press. 